\section{El calor del diseño}

The Heat of Design

Teresa Carreño Vicente

Palabras clave: Termografía, infrarroja, calor, representación, creativa

Key words: Infrarred, termography, heat representation, creative
La Termografía Infrarroja sirve para realizar análisis científicos cualitativos y cuantitativos del calor de las superficies. Hoy en día es muy utilizada en todos los sectores con gran éxito siendo parte fundamental e indispensable en la investigación y en el desarrollo de numerosos proyectos de diseño. de numerosos proyectos de diseño. Termografía Infrarroja Creativa, un uso diferente de esta tecnología, que ofrece una visión distinta de la realidad y una potente herramienta plástica que abre nuevas vías de expresión con las que revolucionar el campo de la representación y la comunicación.

Infrared thermography is currently used with success for scientific analytical purposes in qualitative and quantitative studies of the heat of surfaces. Today it is widely used in all sectors and is essential and indispensable part in the research and development of many design projects.

In this paper we present a brief introduction to Creative Infrared

Thermography. A different approach of reality and a powerful visual arts tool which opens the door to new ways of expression and could entail a revolution in representation and communication.
En su día a día el diseñador afronta, valora e intenta resolver los desafíos que la sociedad presenta. Su actividad supone un intercambio entre tecnología, ciencia e ideas, para descubrir en el entorno y aportar valor. Uno de los instrumentos de los que dispone en la actualidad para realizar su tarea es la termografía Infrarroja. Técnica que le ofrece una herramienta para explorar el medio, pues permite obtener otra visión de la realidad: la del calor. Una radiación invisible al ser humano que percibe por el tacto

En la actualidad esta tecnología es muy utilizada en las distintas industrias. Forma parte indispensable de los procesos de diseño y fabricación de numerosos objetos, así como en los de rediseño, pues también se utiliza para verificar y comprobar tanto el funcionamiento, como el desgaste de los materiales y la eficiencia energética de aquello que se ha construido, y en procesos de mantenimiento facilita mucho la detección de fallos en los sistemas y la localización de averías. A nivel gráfico su uso se está extendiendo, imágenes obtenidas por esta técnica forman parte ya de la publicidad y de numerosos programas de información, divulgación y entretenimiento. Sin embargo su uso como herramienta creativa todavía no es muy frecuente.

La técnica termográfica infrarroja es un método de análisis científico cualitativo y cuantitativo del calor de las superficies, serio y riguroso en sus planteamientos. Mediante una cámara con dispositivos de imagen a distancia, es decir sin contacto, se convierte la radiación infrarroja emitida por sujetos u objetos en una imagen bidimensional en la que se asignan colores a las distintas temperaturas, por lo que pueden visualizarse patrones térmicos que luego se analizan.

La termografía infrarroja se desarrolla a partir del siglo XIX ${ }^{1}$, sin embargo hasta mediados del siglo pasado no comienza el auge de esta técnica de la que tanto se han beneficiado y continúan beneficiándose la ciencia y la sociedad actual. En las últimas décadas se ha reducido el tamaño de los aparatos así como sus costes, lo que ha permitido que sea mucho más accesible. Sus aplicaciones no se circunscriben únicamente al campo del diseño: son múltiples y se usa prácticamente en todos los sectores (medicina, alimentación, vigilancia, edificación, sostenibilidad, enseñanza, aeronáutica...), ya que la técnica no es invasiva, es decir no provoca ningún efecto adverso sobre aquello que es objeto de su estudio ni sobre quien lo realiza.

Es obvio que para realizar estos análisis es necesario tener conocimientos de cómo hay que utilizar la cámara y de cómo se deben interpretar las imágenes. Es más, únicamente un experto sobre el tema objeto del estudio podrá valorar los resultados y realizar una interpretación correcta de los datos obtenidos para poder elaborar un dictamen y ofrecer un diagnóstico.

Ahora bien, no es el propósito de esta comunicación hablar de las características técnicas y científicas de la tecnología. Aunque si se ha considerado que las cámaras térmicas en la actualidad aunque no precisamente baratas, son asequibles, pues sus ventajas amortizan 
pronto el gasto realizado, por lo tanto empiezan a ser numerosas las personas que disponen de ellas. Y una vez que se es propietario de una cámara de este tipo, es normal que llevado por la curiosidad se intente ver el aspecto del calor de aquello que nos rodea.

El diseñador promueve imágenes y manifiesta su voluntad de suscitar nuevas formas e ideas. En el convencimiento de que en su naturaleza existe un explorador -pues para ejercer tiene que representar, lo que implica registrar, reconocer con diligencia cosas, lugares, personas, ideas, incluso a sí mismo- presentamos una breve introducción a la Termografía Infrarroja Creativa. Un uso diferente de una tecnología en la que además de otra visión de la realidad, hemos encontrado una potente herramienta plástica con la que inscribir con medios que le son propios, nuestras relaciones con el mundo exterio y con nuestro imaginario utilizando su propia lengua. Un recurso que abre nuevas vías de expresión, que pensamos pueden ser muy útiles tanto para conocer mejor nuestro mundo, como para el desarrollo de nuestra profesión. Un instrumento que ofrece un nuevo lenguaje para crear, para imaginar, para realizar el discurso que permite comunicar con la sociedad y provocar una reacción en el espectador.

En las imágenes térmicas que proponemos el análisis científico pasa a un segundo plano. Es cierto que ofrecen una visión del entorno de la cual se puede extraer alguna información de cómo es la realidad del calor y de cómo se comportan los materiales, pero siempre se tendrá en cuenta que dicha información no sirve para realizar ningún tipo de diagnóstico, como cualquier termógrafo cualificado nos podría argumentar.

El primer contacto con la técnica lo obtuvimos de un modo casi casual. A partir de una experiencia insólita pero a su vez maravillosa: la solicitud de participar en una exposición realizada con imágenes térmicas sin tener en cuenta los aspectos científicos de la tecnología, es decir desde la estética ${ }^{2} \ldots$ Y encontramos una potente herramienta con la que cuestionarnos el universo, conseguir fines artísticos y obtener conocimiento. En ese momento el explorador se hizo expedicionario y nos embarcamos en la ardua tarea de indagar en lo encontrado.

Desde entonces hasta ahora han proliferado el tipo de imágenes a las que nos referimos. Incluso ya hay quien utiliza la cámara de esta manera, y sabemos que en ciertas escuelas de termógrafos se imparte clase de composición dando importancia al resultado estético de la imagen ${ }^{3}$, pero cuando por primera vez nos enfrentamos al uso de la cámara no encontramos ninguna referencia a esta aplicación de la termografía infrarroja. Podríamos argumentar que realizamos el trabajo por instintito, lo que aunque cierto en parte, no es toda la verdad. Contábamos con un bagaje adquirido a lo largo de nuestra trayectoria. Con estructuras mentales que nos han permitido atender a aquello que sucedía en la imagen. Aun así, es preciso señalar que si bien estas estructuras permitieron afrontar el proyecto, muchas de las cosas que ahora podemos apreciar en este tipo de imágenes no las podíamos ver en ese momento.
Es por ello que en un principio tratamos de escoger temas de por si impactantes o al menos llamativos, y basar las decisiones referentes a la composición en crear una base estructural en la imagen fundamentada en los elementos gráficos del diseño, que nos permitiera tanto a nosotros como al espectador dar sentido y entender lo contemplado. Pues no es ningún secreto que existe un lenguaje plástico visual cuyos elementos permiten expresar lo que queramos, ya que sus efectos tienen carácter universal, se basan en principios físicos objetivos, no dependen del gusto o de la experiencia de los individuos y funcionan con independencia de la técnica artística que se utilicen. Actuar de esta manera nos permitió realizar las imágenes, pero también verificar que la técnica utiliza su propio lenguaje. Un lenguaje con entidad propia e independiente que permite generar un discurso artístico. Este descubrimiento nos llevó a realizar un exhaustivo estudio ${ }^{4}$ - que puede resultar útil tanto a aquel que desee realizar termografías infrarrojas creativas como interpretarlas- sobre el lenguaje plástico-visual en la termografía infrarroja a todos los niveles -morfológico, sintáctico y semántico- valorando asimismo las posibilidades denotativas y connotativas de la imagen térmica y cómo puede afectar todo ello a la representación y a la comunicación.

Parte de este lenguaje y de las posibilidades que ofrece la técnica termográfica infrarroja -que pueden facilitar la labor de quien quiera abordar de este modo la termografía infrarroja- es lo que queremos mostrar. Ahora bien, ante el volumen de lo encontrado ${ }^{5}$ y cuando lo descubierto trasciende lo personal y se muestra universal, es difícil resumir en breves líneas lo hallado, por lo que al considerar lo que se expone, hemos estimado qué podría interesar, a quien decide usar la cámara térmica para crear imágenes desde la estética por primera vez.

Obtener la imagen deseada para realizar un proyecto supone conocer -o al menos intuir- como va a ser dicha imagen. Al realizar una termografía infrarroja no debemos esperar que la apariencia de los sujetos u objetos que van a aparecer en ella sea la que muestra la realidad visible, pues no es esta la realidad que se registra, si no la del calor. Las características de la termografía infrarroja vienen determinadas por la diferencia de temperaturas entre los objetos, por lo que un buen punto de partida sería la recomendación de dedicar un tiempo a reflexionar sobre el tema que se quiere tratar desde esta energía y en cómo se lleva a cabo el proceso termográfico. Al ser la radiación térmica invisible al ojo humano, es aconsejable entender qué es lo que genera la imagen (es decir el calor), cómo funciona, qué hace, cómo se transmite, para saber qué podemos esperar en su relación con los materiales.

La temperatura de los objetos entre otras cosas, depende del fía Infrarroja Creativa. Lenguaie plástico visual en la imagen térmica, Tesis Doctoral, mecanografiado, (por atención del autor), Valencia, Universitat Politècnica de València, http://hdl. handle.net/10251/48528 5 En dicha investigación se exponen 70 conclusiones. les. 2015. Disponible de Salin Car

material del que están hechos, de su forma, del tipo de acabado superficial, la textura que presentan, y de factores externos a ellos, como pueden ser la temperatura ambiente o la humedad. Todo ello afecta cómo actuarán ante la radiación infrarroja y a cómo se va a efectuar la transmisión de energía. El calor se traslada siempre del objeto con 
Fig. 1. Termografía infrarroja, paleta
Rain 900. Cámara Flir T640. Teatro. Teresa Carreño. 2011.

Fig. 2. Termografía infrarroja, paleta Rain 900. Cámara Flir T640. Torre, Rea Monasterio de San Lorenzo de El
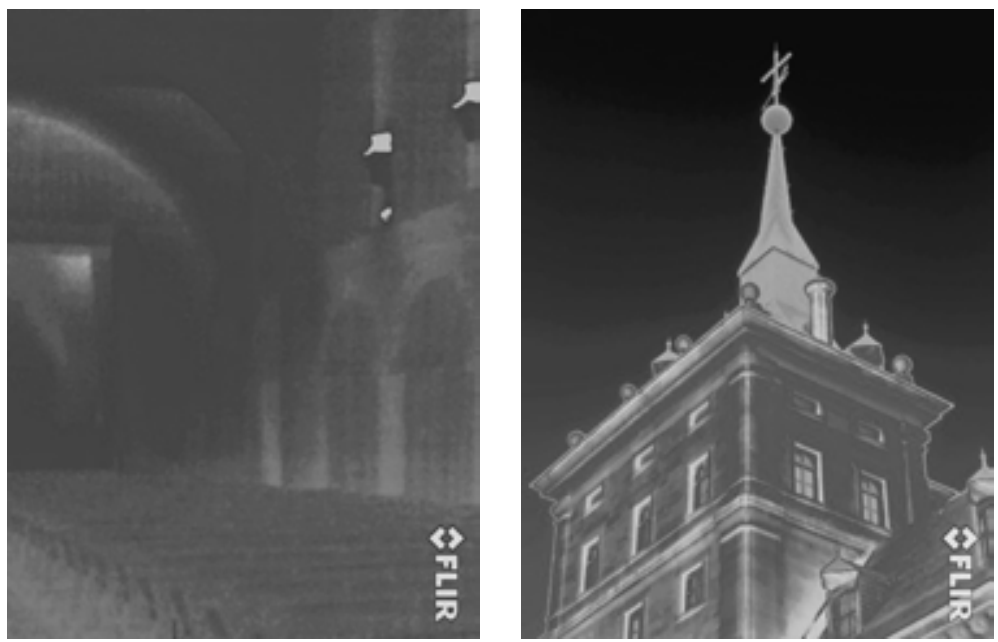

mayor temperatura al de menor hasta igualar sus temperaturas, y a nuestro alrededor continuamente de manera natural se está produciendo intercambio de energía.

La experiencia nos ha demostrado que vale la pena dedicar un tiempo a valorar cómo pueden actuar los elementos que se presentan y si puede haber intercambio de calor en aquello que queremos registrar, pues puede darse el caso de que aunque el tema sea visualmente muy interesante, la respuesta de los materiales no sea la que imaginamos o que todos ellos tengan una temperatura similar, lo que dará lugar a una imagen térmica carente de interés. La imagen que presentamos a continuación (figura 1) es un buen ejemplo de ello. Está realizada en un espacio arquitectónico único, y sin embargo no caímos en la cuenta de que ese interior, rodeado de gruesos muros, mantenía todo el recinto y su contenido con temperaturas semejantes por lo que aunque pudimos realizar imágenes térmicas, éstas no ofrecían visualmente contraste resultando bastante planas.

Dedicar unos minutos a pensar si aquello que queremos termografiar disipa el calor suficiente como para obtener una buena imagen térmica permite evitar situaciones como la descrita, y obtener termografías infrarrojas como la que se muestra a continuación en la que si se tuvo en cuenta este factor (figura 2). La imagen está realizada cuando el día deja paso a la noche, en el atardecer, momento en el que el calor recibido por los edificios a lo largo de la jornada vuelve a la atmósfera.

Una vez elegido el tema es preciso seleccionar lo que se desea que aparezca en la termografía infrarroja, es decir tener en cuenta los elementos que queremos que formen parte de la imagen -máxime si ésta va a formar posteriormente parte de un proyecto- pues sus características afectarán al desarrollo del mismo. La cámara térmica muestra en el visor aquello que va registrar, por lo tanto es posible observar y verificar a través de él, si aquello que se escoge está dotado de cierta armonía y expresa lo que queremos.

Componer es dar sentido, organizar, ordenar el espacio en la mirada, y aqu
Fig. 3. Fotografía color. Cámara Flir T640. Fachada oeste del Real Monasterio de San Lorenzo de El 2011.

Fig. 4. Termografía infrarroja, paleta Rain 900. Cámara Flir T640. Facha oeste del Real Monasterio de San

Teresa Carreño. 2011. es cuando entra en juego la experiencia y el estilo de cada uno. La imagen termográfica infrarroja posee su propio lenguaje pero como cualquier otro tipo de imagen, contiene elementos que le dan forma y estructuran: los elementos gráficos. Estos elementos no pierden sus propiedades por for mar parte de una imagen térmica, sin embargo su procedencia puede ser distinta de la de aquellos que forman la fotografía correspondiente, adquirir diferente significado, articularla de otra manera y algunos incluso, no tener equivalente en el visible. Además es conveniente tener en cuenta que cuando la relación del color con la realidad visible no existe, como sucede en la imagen térmica -puesto que representa la temperatura y no la luz- adquieren mayor significación. Por todo ello conocer a priori algo de lo que puede suceder en la imagen puede ayudar a la hora de observar a través del visor.

Son muchos los materiales -algunos de ellos abundantes en el entorno, como el agua y el vidrio- cuyo comportamiento ante el calor es distinto de aquel que estamos acostumbrados a observar de ellos en nuestra experiencia visible. Una de las tareas que abordamos en la investigación fue comparar la imagen térmica con la fotográfica para ver qué elementos gráficos desaparecían, cuáles eran nuevos, y en los que existían en ambas imágenes comprobar si eran semejantes o cambiaba su valor. De este modo pudimos distinguir valores del referente que difieren en la imagen del calor de aquella del visible. Hecho de gran importancia puesto que son los que modifican la expresión. (figuras 3 y 4)

Como se puede observar, las dos imágenes expuestas (obtenidas simultáneamente) son muy distintas entre sí y la diferencia no viene dada sólo por el color. La fotografía muestra la imagen de una escena por la noche donde se pueden distinguir en el edificio del fondo algunas ventanas, tres de ellas iluminadas. El resto de los elementos se diluyen en las sombras. En la termografía infrarroja estas zonas se revelan mostrando con todo detalle no solo la fachada del edificio -desde las chimeneas del tejado hasta el piso bajo- también es posible apreciar en la imagen partes que están en planos posteriores. Si nos fijamos en la zona correspondiente a las ventanas se puede reparar en que todas ellas tienen el mismo valor, no existiendo diferencias entre las que están iluminadas y las que no.

En la termografía infrarroja de este otro ejemplo (figura 5), se pueden observar unas manos infantiles retirando velas de cumpleaños de una ta ta. En la acción es posible adivinar que un niño va quitando las velas y otro las va sujetando. En este caso no es difícil creernos cuando decimos que la imagen térmica difiere bastante de su correspondiente en el visible. La
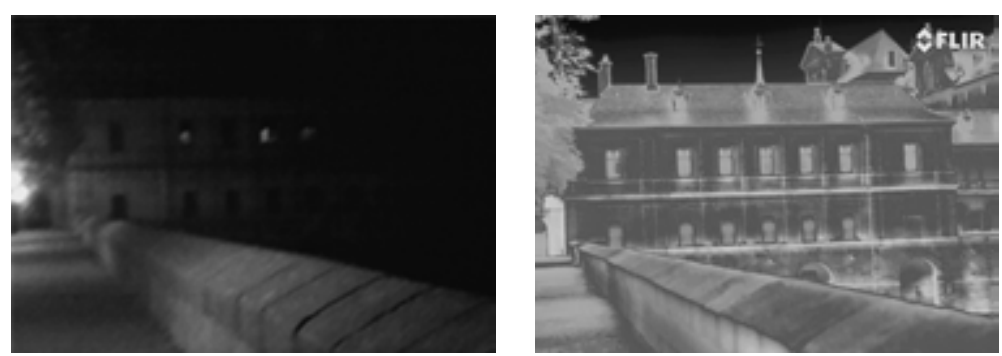

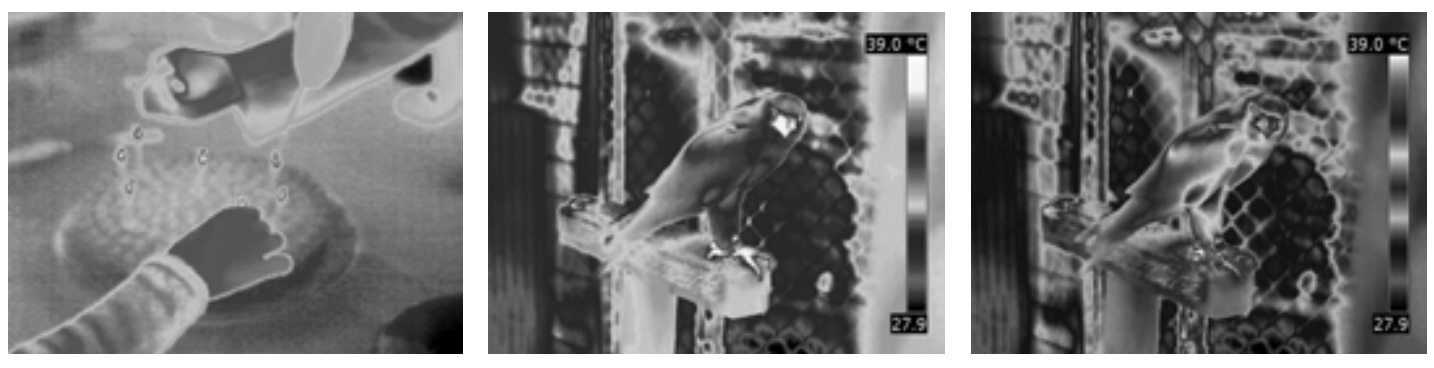

Fig. 5. Termografía infrarroja, pale Rainbow. Cámara NEC TH 8700. Cumpleaños. Teresa Carreño. 2012 Fig. 6. Termografía infrarroja, paleta Mgrain. Cámara Flir T640. H

Fig. 7. Termografía infrarroja, paleta Hotcoal. Cámara Flir T640. Halcón harris. Teresa Carreño. 2011

\section{Bibliografía}

CARREÑO, TERESA: Termografia Infrarroja Creativa. Lenguaje plástico visual en la imagen térmica, Tesis Doctoral, mecanografiado, (por atención del autor), Valencia, Universitat Politècnica de València, les, 2015 . Disponible en.len lineal http//hdl handle net/10251/48528 VOLMER, M MOLLMANN, KP. (Traducción de ROYO PASTOR, R. Termografía Infrarroja, Valencia, Universitat Politècnica de València, 2013. mesa, la tarta (decorada con pequeñas pastillitas de colores) y el resto de los elementos que están sobre la mesa se han unificado en el color formando el fondo de la imagen, en la que una fuerte diagonal con un movimiento en "S" en su parte central marca la composición. Al realizar esta termografía la autora reconoce que alarmada dejó de termografiar al pensar erróneamente que las velas estaban encendidas.

Esta imagen sirve para mostrar cómo elementos que pasarían desapercibidos en una imagen fotográfica -pues el pábilo de una vela apagada prácticamente no se vería en una situación como la que se presenta- se muestran claramente en una termografía infrarroja. Pero también sirve para señalar e introducir otra de las características de la técnica que puede resultar muy interesante para el creativo: la referente al color.

El color en termografía infrarroja se utiliza para mostrar las temperaturas de los sujetos u objetos representados, por lo que a cada una de ellas se le asigna un tono. Esto significa -como habrán podido observar en las termografías infrarrojas que acompañan al texto- que dichos colores no se corresponden con los que muestran las superficies en la realidad visible.

Las cámaras térmicas poseen distintas paletas que permiten visualizar las diferencias de temperatura que se dan en la imagen todo ello con el fin de aumentar o disminuir los contrastes que se presentan en ella para poder realizar un buen análisis científico. Cada paleta muestra con mayor definición una parte de la realidad analizada aportando información diferente, es decir, que se complementan entre ellas. Es posible cambiar de paleta en la cámara, pero también a posteriori en el ordenador, con el software con el que se analizan las imágenes. Esta peculiaridad que ofrece la técnica amplia muchísimo las posibilidades de representación y de expresión, pues por cada imagen que realizamos en realidad obtenemos un abanico de imágenes sobre el mismo tema con distintos colores y contrastes. Y es sabido que ambas características son fundamentales en la expresión y en la comunicación. (figuras 6 y 7 )

La misma imagen puede transmitir sensaciones muy distintas dependiendo de los colores que muestre, pues estos modifican las relaciones compositivas que aparecen en ella. También existe la posibilidad de trabajar en blanco y negro, y con cada paleta en positivo y en negativo, e incluso hay paletas con las que obtener termografías infrarrojas con un marcado estilo gráfico. (figura 8
Fig. 8. Termografía infrarroja, paleta Medical. Cámara Flir T640. Búho

Fig. 10. Termografía infrarroja y dibujo. De la serie smog. Teresa

Fig. 9. Termomontaje infrarrojo. D la serie aire. Teresa Carreño. 2013

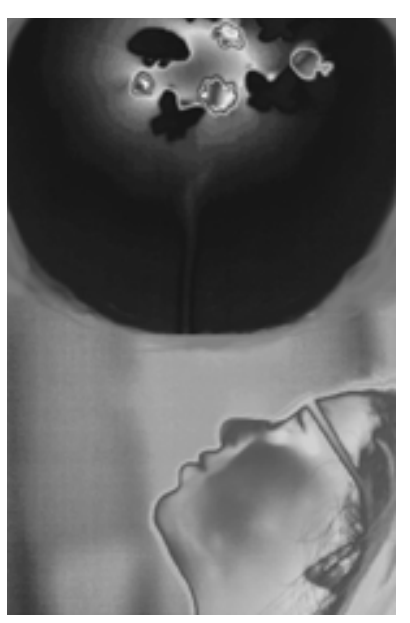

Teresa Carreño Vicente

Profesora en la Escuela Superio de Diseño del Centro Español d Nuevas Profesiones de Madrid de tecnología. Artista plástico-visual, diseñadora estauradora de obras de arte. Desde 1986 combina su labor docente con la profesional e investigadora. Ha participado en numerosas exposiciones, proyectos artísticos proyectos de diseño.
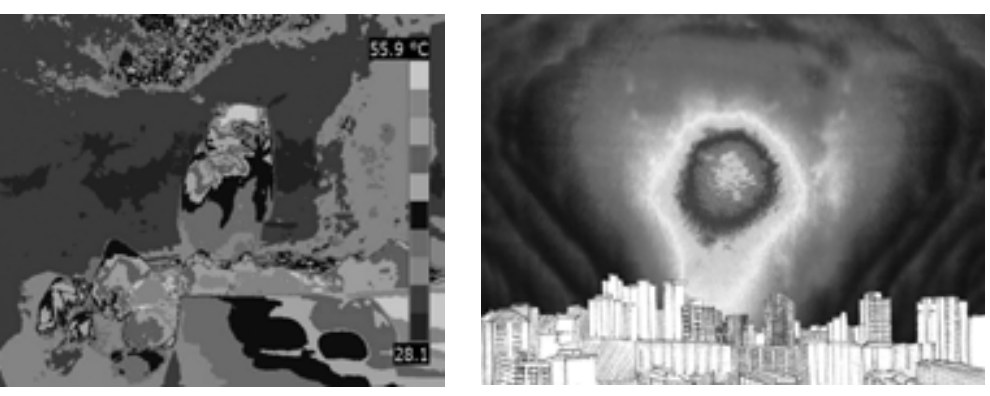

Llegados a este punto seguramente hay quien se pregunte si a parte de representar la realidad, es posible crear imágenes que muestren una ficción. Al igual que en un estudio fotográfico se pueden establecer las condiciones para realizar una fotografía determinada, podemos crear la situación térmica que nos permita realizar imágenes fruto de nuestra fantasía. Solo es cuestión de aplicar nuestros conocimientos sobre el calor y usar la imaginación.

Son muchas más las características de la imagen térmica que difieren de la visible y muchas las posibilidades que ofrece en lo que concierne a la narración. Todas ellas hacen posible describir y expresar, mostrar nuestras relaciones con el espacio y el tiempo, la presencia, la ausencia, lo imprevisto, lo sugerido, lo imaginario. Es más, una vez obtenidas las termografías infrarrojas se puede proceder cómo con cualquier otra imagen, pudiendo realizar termomontajes (figura 9) 0 interactuar con otras técnicas (figura 10).

Es imposible como ya se ha indicado, abordar en estas líneas todos los atributos de la imagen termográfica infrarroja. Su capacidad para mostrar la huella del calor, gases invisibles al ojo humano, el interio de una bolsa negra de basura, llenar el cielo de colores, reflejos en los sitios más insospechados... Es por ello que esperando que lo aquí expuesto sea útil a quien quiera que se inicie en la termografía infrarroja creativa, insistimos en que hay ciertas circunstancias que favorecen el intercambio de calor, y en la importancia de comprender y entender que el comportamiento de los diferentes materiales es distinto ante e calor que ante la radiación visible, ya que todo ello afecta a la representación. Conocer estas condiciones y las posibilidades gráficas que ofrece la técnica permitirá, al abordar la captura de la imagen térmica de manera creativa, estar atentos a los elementos que se hacen visibles en la termografía infrarroja. De este modo el autor obtendrá recursos que le allanarán el camino y adquirirá la capacidad avanzar por sí mismo, tanto a la hora de termografiar como a la de previsualizar el resultado que logrará en la imagen.

Utilizada de esta manera, la termografía infrarroja ofrece un espacio donde buscar y encontrar originales y nuevas formas de expresar y comunicar ideas, pues las sensaciones visuales que se evidencian exclusivamente en el proceso termográfico infrarrojo abren nuevos horizontes a la retórica expresiva. Un territorio -el del calor- todavía virgen, que cualquier creativo puede explorar y usar en la elaboración de sus proyectos. 